\title{
P3-Like Brain Waves in Normal Monkeys and in Monkeys With Medial Temporal Lesions
}

\author{
Ken A. Paller \\ Department of Neurosciences, School of Medicine \\ University of California, San Diego
}

\author{
Stuart Zola-Morgan and Larry R. Squire \\ Veterans Administration Medical Center, San Diego \\ and Department of Psychiatry, School of Medicine \\ University of California, San Diego
}

\author{
Steven A. Hillyard \\ Department of Neurosciences, School of Medicine \\ University of California, San Diego
}

\begin{abstract}
The human brain produces a characteristic electrical response to relevant events that occur unexpectedly. Recent reports have suggested that a prominent part of this event-related brain potential - the $\mathrm{P} 3$ wave - may be related to memory functions and may arise from activity within the medial temporal lobe, especially the hippocampus. The latter idea was tested by means of epidural recordings of brain waves in monkeys. Responses to deviant auditory stimuli bore a close resemblance to $\mathrm{P} 3$ waves recorded from human subjects under comparable conditions. Monkeys with bilateral lesions of the medial temporal lobe still produced P3-like brain waves, which indicates that medial temporal brain structures are not critical for their generation.
\end{abstract}

Perceptual and cognitive events in humans are reliably associated with measures of brain electrical activity recorded noninvasively from the scalp and extracted from the electroencephalogram using signal averaging. These event-related brain potentials (ERPs) provide a way to study neural mechanisms of information processing (Donchin, 1984; Gaillard \& Ritter, 1983; Galambos \& Hillyard, 1981; Hillyard \& Kutas, 1983).

The P3 wave (also known as P300) is an ERP that is typically elicited by unexpected or informative stimuli, such as an unpredictable change in a repetitive sequence of events (see reviews by Fabiani, Gratton, Karis, \& Donchin, 1987; Pritchard, 1981). P3 waves can be elicited by suitable stimuli in auditory, visual, or somatosensory modalities (e.g., Snyder, Hillyard, \& Galambos, 1980). P3 amplitude declines when attention is diverted from the stimuli (Wickens, Kramer, Vanasse, \& Donchin, 1983) or when the subject is uncertain about having correctly perceived the unexpected event (Hill-

This research was part of Ken A. Paller's doctoral dissertation for the Neurosciences Program of the University of California, San Diego. It was supported by the Medical Research Service of the Veterans Administration and by National Institute of Mental Health Predoctoral Fellowship MH09128 to Ken A. Paller.

We thank Fred Blesch, Jon Hansen, Carol Micheletti, and Jeremy Phillips for technical support; Mortimer Mishkin for preparing lesions in three monkeys; and Steve Foote, Bob Galambos, Marta Kutas, and Chris Wood for helpful advice.

A research protocol describing all aspects of the present study that relate to the use of animals was approved by the Animal Subjects Committees of the Veterans Administration Medical Center, San Diego and the University of California, San Diego.

Correspondence concerning this article should be addressed to Ken A. Paller, who is now at Neuropsychology Laboratory (116B1), Veterans Administration Medical Center, West Haven, Connecticut 06516. yard, Squires, Bauer, \& Lindsay, 1971; Ruchkin \& Sutton, 1978). The latency of $P 3$ depends primarily on the time required for evaluation and classification of the eliciting stimuli (Kutas, McCarthy, \& Donchin, 1977; McCarthy \& Donchin, 1981).

One hypothesis put forth to explain the functional properties of the P3 wave is that this ERP is a manifestation of a fundamental mechanism in the encoding of memories (Donchin, 1981). Other proposals have linked $P 3$ waves to constructs such as information delivery (Sutton, Tueting, Zubin, \& John, 1967), decision closure (Desmedt, 1981), and stimulus value (Sutton \& Ruchkin, 1984). Controversy over the psychological correlates of P3 may stem in part from the fact that these waves are elicited as part of a complex of overlapping ERP components that includes earlier modality-specific components, various late positive components, and several types of slower components (see Sutton \& Ruchkin, 1984). One type of late positive wave, for example, is larger over anterior scalp locations and is elicited relatively automatically, even by stimuli not in the focus of attention (called "P3a" by Squires, Squires, \& Hillyard, 1975). ERPs conventionally identified as P3 ("P3b") have a scalp distribution largest near the central and parietal midline and are enhanced when attention is directed to the stimuli. There is currently disagreement among investigators over the criteria by which to distinguish among different ERP components, but a rigorous classification of distinct late positive waves should become increasingly feasible as further information becomes available about their respective neural bases.

The neural generators of $\mathrm{P} 3$ waves have been investigated in human subjects using surface and depth electrical recordings as well as magnetic recordings (see review by Wood et al., 1984). Based on such data, several investigators (Halgren et al., 1980, 1983; Okada, Kaufman, \& Williamson, 1983) have proposed that generators contributing to $\mathrm{P} 3$ are localized 
in the medial portion of the temporal lobe (i.e., hippocampus and amygdala). Observations that P3 amplitude is correlated with subsequent memory performance (Fabiani, Karis, \& Donchin, 1986; Karis, Fabiani, \& Donchin, 1984; Neville, Kutas, Chesney, \& Schmidt, 1986; Paller, Kutas, \& Mayes, 1987; Sanquist, Rohrbaugh, Syndulko, \& Lindsley, 1980) are consistent with this proposal, given that medial temporal lobe structures have been implicated in memory functions (Mishkin, 1978; Scoville \& Milner, 1957; Zola-Morgan \& Squire, 1985; Zola-Morgan, Squire, \& Amaral, 1986).

Ethical and methodological considerations place severe limitations on the study of ERP source localization in human subjects. Many possible source configurations can produce the same surface field, because currents in a volume conductor sum linearly by Helmholtz's principle of superposition. Thus, without additional evidence, extracranial recordings of potential fields or magnetic fields cannot unambiguously define the intracranial generators (Vaughan \& Arezzo, 1988). In the case of P3, extracranial recordings have not been sufficient to differentiate among candidate generator locations that have been proposed in frontal, parietal, and medial temporal areas (see Knight, 1984; Vaughan \& Ritter, 1970). ERP source localization from magnetoencephalographic evidence requires further assumptions, in order to establish a correspondence between magnetic and electrical event-related activity. Due to the differential sensitivities of the two techniques, however, this correspondence may be difficult to verify for cases in which multiple brain areas are active concurrently. In addition, available techniques for localizing sources of magnetic fields generally entail the restrictive assumption that the evoked magnetic field can be modeled as arising from a single dipole source. Recordings from intracranial electrodes may avoid many of these problems, but electrode placements are dictated by clinical needs and survey a limited number of brain areas. Accordingly, much doubt remains concerning the neural origins of $\mathrm{P} 3$ waves in humans. The sensitivity of P3 to psychopathological conditions such as schizophrenia and dementia (e.g., Begleiter \& Porjesz, 1986; Karrer, Cohen, \& Tueting, 1984; Kutas \& Hillyard, 1985; Michalewski, Rosenberg, \& Starr, 1986) suggests that a better understanding of the neural bases of this ERP will have clinical significance.

Conventional paradigms for eliciting $\mathrm{P} 3$ waves in humans have recently been adapted for studies in nonhuman primates in order to develop animal models of this ERP (Arthur \& Starr, 1984; Neville \& Foote, 1984; Paller, Zola-Morgan, Squire, \& Hillyard, 1982, 1984; Pineda, Foote, \& Neville, 1987). The demonstration of a correspondence between $P 3-$ like potentials in humans and monkeys would open the door to a variety of techniques for investigating the mechanisms responsible for the intracranial electrogenesis of these ERPs. Here, we report that late positive ERPs recorded from monkeys showed strong similarities to P3 waves recorded from humans. Auditory stimuli were presented without conditioned significance in the "passive" condition, whereas these same stimuli were given relevance in the "active" condition. In addition, ERPs were obtained from operated monkeys to test the hypothesis that the hippocampus, amygdala, and adjacent cortical areas play an essential role in generating P3like waves in monkeys.

\section{Experiment 1: Passive Condition}

\section{Method}

Animals. Eight Cynomolgus monkeys (Macaca fascicularis) were studied. Five monkeys sustained bilateral ablations of hippocampus, amygdala, and overlying cortex. Two of these monkeys were studied both pre- and postoperatively. Previous studies have shown that monkeys with such lesions fail memory tasks analogous to those failed by human amnesic patients (Mishkin, 1978; Zola-Morgan \& Squire, 1985).

Surgery. Following anesthesia (sodium pentobarbital, $30 \mathrm{mg} / \mathrm{kg}$ ), skin, fascia, and temporal muscles were retracted and the surface of the skull was cleaned. Stainless steel screws with wire leads were implanted, each penetrating the skull surface approximately 3-5 mm. Although species differences in the spatial relations between skull landmarks and cortical areas precluded a precise correspondence with the ten-twenty system for electrode placements in humans (Jasper, 1958), labels from this system were used to designate electrode locations in monkeys. The locations of implanted electrodes are depicted schematically in Figure $1(\mathrm{Fpz}, \mathrm{Fz}, \mathrm{Cz}$, and $\mathrm{Pz}$ on the midline; $\mathrm{C} 3$ and $\mathrm{P3}$ on the left side; $\mathrm{C} 4$ and $\mathrm{P} 4$, corresponding locations on the right side; $F$ implies frontal, $C$ implies central, and $P$ implies parietal). A reference electrode was implanted on the midline 1-2 $\mathrm{mm}$ below inion. (Occasionally, it was necessary to use an earlobe or subdermal electrode as the reference, but a separate test showed negligible differences between P3-like ERPs recorded with these different methods; Paller, 1986.) To provide additional stability, T-shaped holes were drilled to enable several flat-head screws to be wedged under the skull and bolted in place. After the wire leads were attached to a plastic connector, screws and wires were covered with acrylic. Muscle and skin were sutured, leaving the top of the connector exposed.

Bilateral medial temporal lobectomies were performed separately also under sodium pentobarbital anesthesia $(30 \mathrm{mg} / \mathrm{kg})$. Two craniotomies were made on each side. The amygdala was approached by elevating the frontotemporal junction and entering the brain medial to the anterior tip of the rhinal sulcus. Gray matter anterior to the rostral portion of the hippocampus and medial to the white matter of the temporal lobe was aspirated with an 18-ga. needle. The hippocampus was approached by elevating the occipitotemporal convexity and entering the brain medial to the occipitotemporal sulcus and caudal to entorhinal cortex. Ablations included the hippocampus proper, dentate gyrus, subicular cortex, parahippocampal gyrus (area TF-TH of Bonin \& Bailey, 1947), perirhinal cortex, and entorhinal cortex. The upper surface of the lateral ventricle served as a dorsal boundary of the lesion, which spared the temporal stem (ZolaMorgan, Squire, \& Mishkin, 1982).

Postmortem histological analyses verified the extent of the lesion in each case (Figure 2A). Brains were fixed in sugar/formalin and embedded in albumin. Frozen sections were cut at $50 \mu$ and every fifth section was stained with thionin for Nissl substance. Figure $2 B$ shows that damage to the hippocampus and to the amygdala was nearly complete in all monkeys. Posterior portions of the hippocampus ( $5 \mathrm{~mm}$ or less) were spared in 4 monkeys. Anterior portions of the medial nucleus of the amygdala were spared in all monkeys, but the cells appeared shrunken and gliotic. In addition, lesions included $70-90 \%$ of the allocortex of the entorhinal area bilaterally. Damage to area TF-TH was limited to about $30 \%$ in 2 monkeys (M2 and M5) but included over $90 \%$ in the other 3 monkeys (M1, M3, and M4). In all monkeys, damage to less than $15 \%$ of inferotemporal cortex (area TE of Bonin \& Bailey, 1947) probably resulted from mechanical pressure applied during the elevation of the occipitotemporal convexity; in Monkey M1, 40-50\% of area TE was damaged bilaterally due 


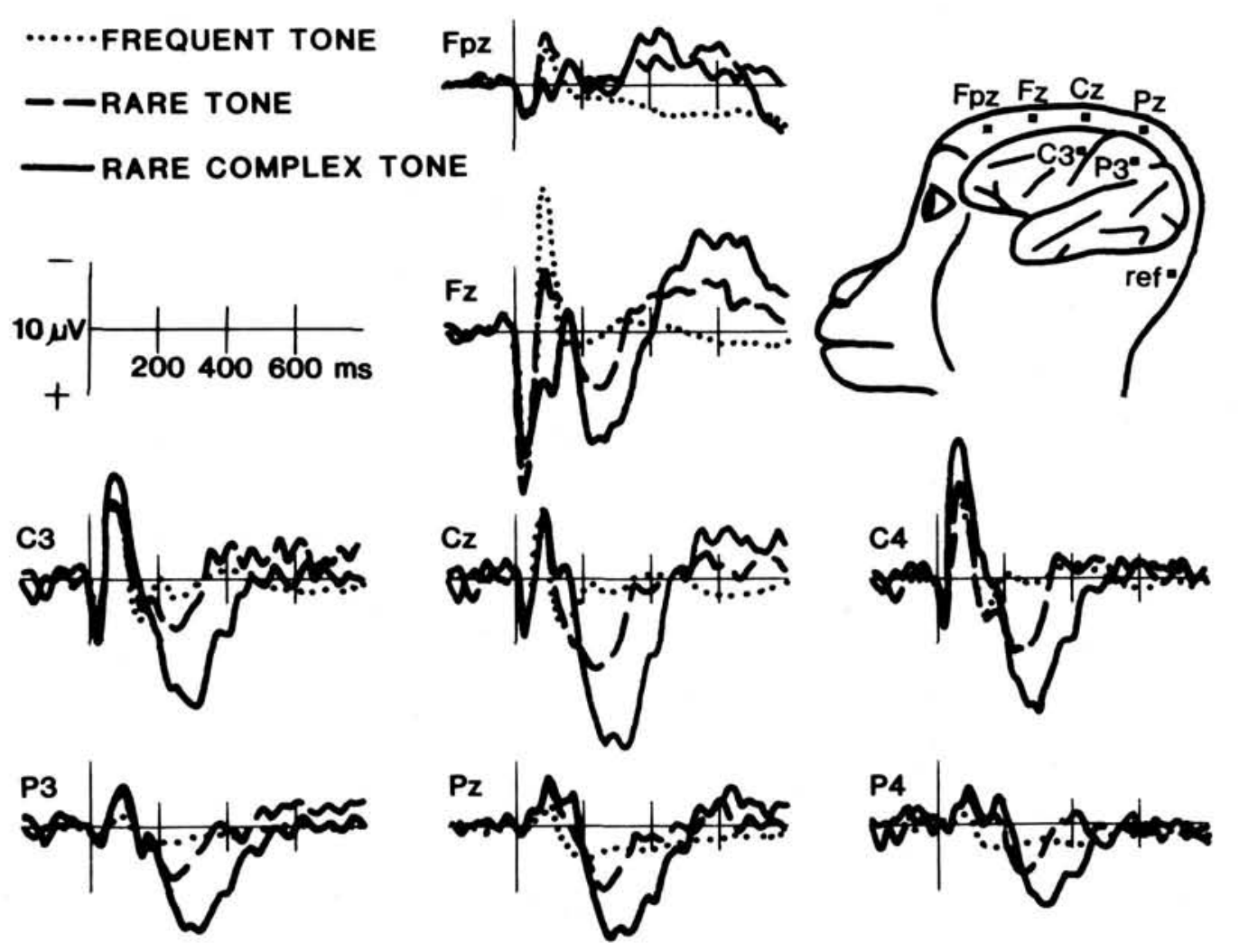

Figure 1. Event-related brain potentials (ERPs) elicited during the passive condition from a group of five intact monkeys. (ERPs to the three types of tones are shown over a 1-s analysis epoch with a 200ms baseline. Positive activity recorded between the elcctrode above each waveform [corresponding locations shown at right] and a noncephalic reference electrode [ref] is plotted as a downward deflection.)

to infarction. The tail of the caudate was damaged unilaterally in Monkey M4. In all monkeys, gliosis was observed throughout the fornix and in the medial mammillary nucleus at the site of termination of the fornix.

Procedure. The stimulus sequence in the passive condition included $1450-\mathrm{Hz}$ pure tones $(80 \%), 300-\mathrm{Hz}$ pure tones $(10 \%)$, and frequencymodulated ("complex") tones with a mean frequency of $125 \mathrm{~Hz}$ $(10 \%)$. All stimuli were $100 \mathrm{~ms}$ in duration and were delivered in random order at a rate of $1 / \mathrm{s}$ while the monkey sat in a primate chair inside a sound-attenuating chamber. Electrical activity was amplified (bandpass $0.15-300 \mathrm{~Hz}$ ), tape-recorded, and digitized at a rate of 256 Hz. ERPs were measured at multiple latencies, but the primary measurement of P3-like activity was the mean amplitude over the $200-350 \mathrm{~ms}$ latency range, with respect to a $200-\mathrm{ms}$ prestimulus baseline.

ERPs were recorded from human subjects in conditions analogous to those described for monkeys. Stimulus sequences were presented to subjects who were not given any explicit instructions regarding the stimulus sequences. Recordings were made from $\mathrm{Ag}-\mathrm{AgCl}$ electrodes affixed to the scalp with collodion at locations shown schematically in Figure 3. The reference electrode was placed over the left mastoid. Electrical activity was amplified (bandpass $0.15-60 \mathrm{~Hz}$ ) and digitized at a rate of $170 \mathrm{~Hz}$. In human subjects, eye movements were monitored using an electrode located below the right eye, whereas in monkeys, eye movements were monitored in the Fpz channel. Following artifact rejection, the number of responses averaged for each of the rare stimuli was approximately 250 for monkeys (60-min sessions) and 40 for humans (10-min sessions).

\section{Results and Discussion}

ERPs recorded in the passive condition and averaged over 5 normal monkeys are shown in Figure 1. Two large deflections were apparent in the first $100 \mathrm{~ms}$ after stimulus onset. At a latency of about $30 \mathrm{~ms}$, a positive ERP peaked at frontal and central electrodes; whereas at latencies between 50 and $100 \mathrm{~ms}$, negative deflections were apparent at all electrodes. The present report, however, will focus on the subsequent positive waves that were elicited by rare stimuli at latencies between 100 and $500 \mathrm{~ms}$ after stimulus onset. The amplitude of the positivity was maximal at the $\mathrm{Cz}$ electrode, slightly smaller at adjacent electrodes, and minimal at the Fpz electrode. For the rare complex tone, the peak at $\mathrm{Cz}$ occurred at about $300 \mathrm{~ms}$ after stimulus onset (mean latency $=278 \mathrm{~ms}$, $S E=27 \mathrm{~ms}$ ); for the rare pure tone, the peak was about 50 ms earlier and the amplitude was considerably smaller. The relation between these positive waves (provisionally referred to as P3-like ERPs) and ERPs that have been designated P3 or $\mathrm{P} 300$ in human studies will be discussed below. 

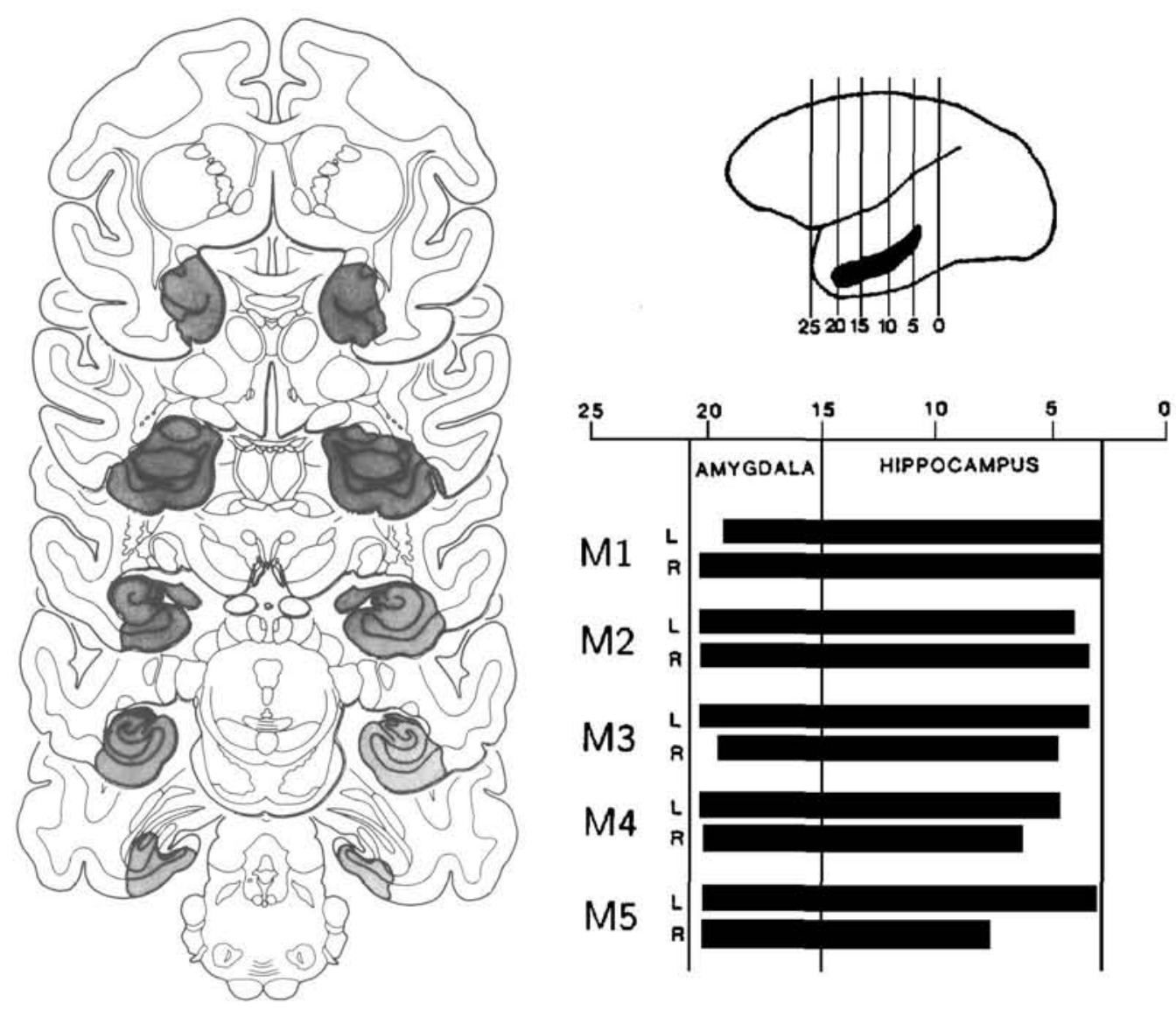

Figure 2. A: Tracings of coronal brain sections showing the extent of bilateral medial temporal damage (shaded region) in a representative monkey (M4). B: Histological results for amygdala and hippocampus for individual monkeys. (Damaged areas are indicated separately for left side and right side [L and R, respectively]. Numerals indicate the approximate distance in $\mathrm{mm}$ from the interaural plane.)

Late positive waves were also recorded from human subjects in response to the rare stimuli, as shown in Figure 3. A number of similarities between the results from the two species can be noted. The largest effects of stimulus type were apparent in late positive deflections between about 100 and $400 \mathrm{~ms}$ after stimulus onset. Late positive ERP amplitude was greatest to the rare complex tone, intermediate to the rare pure tone, and smallest to the frequent pure tone. The distribution of these ERPs across the scalp was broad, with a maximum at the $\mathrm{Cz}$ electrode.

In monkeys with medial temporal lobectomies, ERPs obtained during the passive condition (Figure 4) included late positive waves similar to those recorded from the intact group. The peak amplitude for the ERP to the rare complex tone occurred at the $\mathrm{Cz}$ electrode (mean latency $=259 \mathrm{~ms}, S E=$ $12 \mathrm{~ms}$ ). A three-way analysis of variance (ANOVA; Group $\times$ Stimulus Type $\times$ Electrode Location) showed that measurements of the late positive activity (mean amplitude over the 200-350 ms latency range) did not differ significantly between the operated group and the intact group, $F(1,4)=3.0$. Nor was the interaction of group with electrode location significant, $F(7,28)=1.0$. ERP amplitude measurements for mid- line electrodes for each group are shown in Table 1. Peak amplitude and mean amplitude measurements over various latency ranges yielded basically similar results (see Paller, 1986). As suggested earlier, stimulus type had a significant influence on the late positivity, $F(2,8)=12.7, p<.003$. The only other significant effect was an interaction between stimulus type and electrode, $F(14,56)=3.4, p<.001$, which largely resulted from the small ERP differences related to stimulus type at the most anterior electrode $(\mathrm{Fpz})$.

In a further analysis of the effect of stimulus type, the ERP to the frequent tone was subtracted from the ERP to the rare complex tone. Mean amplitude measurements over the 200$350 \mathrm{~ms}$ latency range, as plotted in Figure 5, showed that the topography of this ERP difference was highly similar between the normal and operated groups [ANOVA of Group $\times$ Electrode): main effect of group, $F(1,4)=0.2$; Group $\times$ Electrode interaction, $F(7,28)=0.6$.] There was a general tendency, however, for ERPs from the operated group to be somewhat more negative than ERPs from the intact group (Table 1). When the mean amplitude measurements were analyzed separately for each stimulus type, ERPs to the frequent tone were found to be significantly more negative in the operated group 


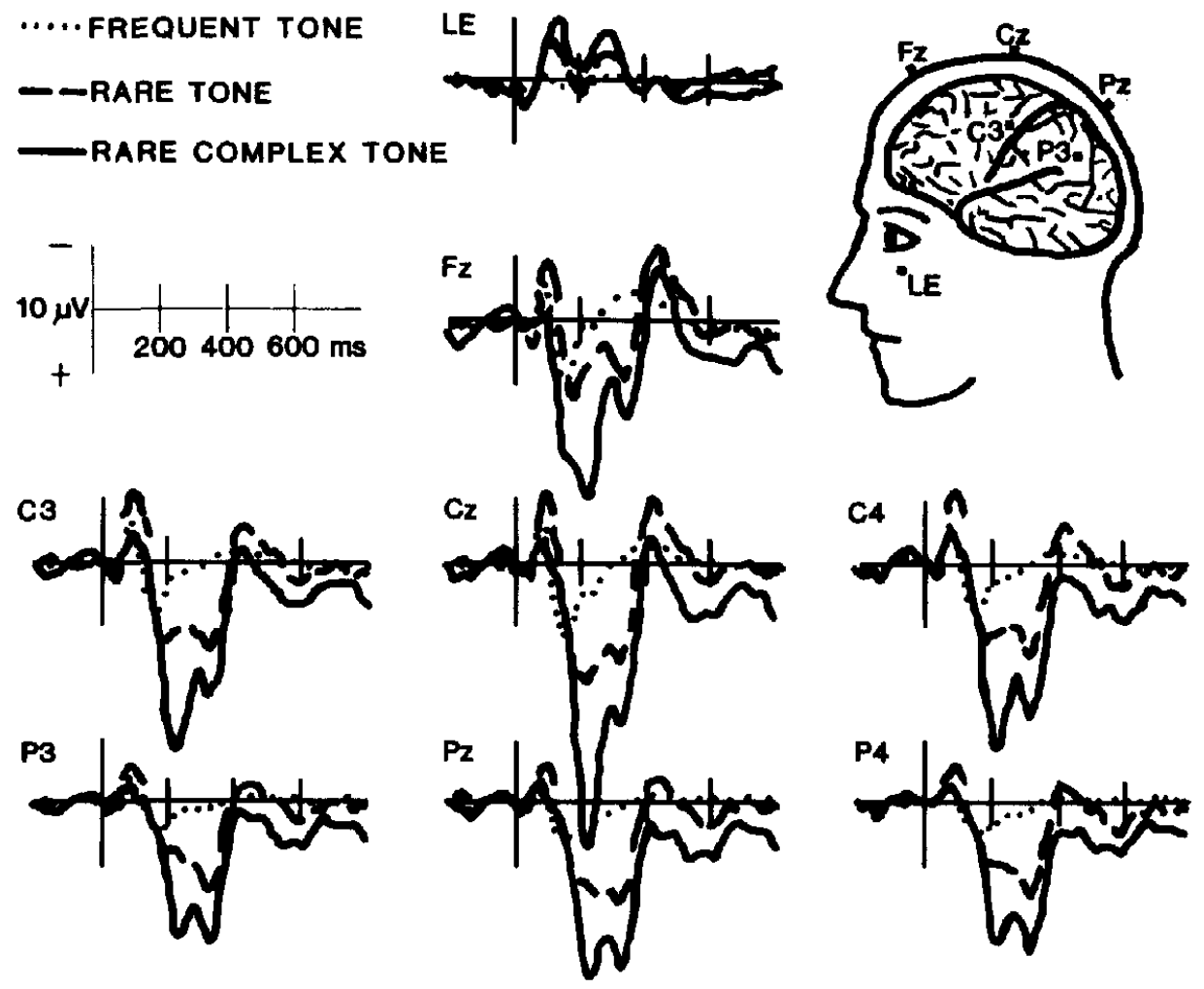

Figure 3. Event-related brain potentials elicited during the passive condition from a group of five human subjects. (LE channel monitored eye movement.)

than in the intact group, $F(1,4)=17.2, p<.014$. This group tendency was also apparent (though nonsignificant) for ERPs to the rare pure tone, $F(1,4)=2.0$, and ERPs to the rare complex tone, $F(1,4)=0.7$. The large negative waves elicited by the frequent tone in the operated groups may be akin to ERPs hypothetically linked to orienting in humans (e.g., Rohrbaugh \& Gaillard, 1983). Orienting responses to stimuli in the passive condition presumably should habituate rapidly; however, it has been noted that animals with hippocampal lesions show "hyperreactivity" or deficient habituation of the orienting response (Douglas, 1967; Meissner, 1966; O'Keefe \& Nadel, 1978; Vinogradova, 1970). Thus these negative responses may reflect continued orienting in monkeys with medial temporal lobectomies, but this interpretation will require further verification.

Because 2 of the monkeys were studied in the passive condition both before and after lesions were made, their electrophysiological results were subjected to a within-subjects comparison. P3-like ERPs were elicited during two sessions before surgery as well as during two sessions after surgery (Figure 6). ERP measurements for each monkey are shown in Table 2. Again, negative waves were elicited by the frequent tone, but only after surgery. These negative waves were largest at frontal electrodes and were also apparent in the ERPs to the rare pure tone. Although late positive ERPs elicited by the rare complex tone were smaller after surgery at some electrodes (especially lateral parietal electrodes), the late positive waves were relatively unchanged at $\mathrm{Fz}$ and $\mathrm{Cz}$ electrodes, where P3-like potentials from intact monkeys were largest.
Overall, the results did not demonstrate a consistent effect of medial temporal lobectomy on P3-like ERPs. The primary difference between ERPs elicited from the two groups was an enhanced anterior negativity in monkeys with medial temporal lesions, especially in response to frequent tones. Measurements of the late positive waves were not significantly different between the groups. Within-subject comparisons in two monkeys revealed that late positive waves were reduced in amplitude in one case but practically unchanged in the other case. Postsurgical changes may have included amplitude changes due to superimposed negative waves or, in the two within-subjects comparisons, to habituation (which would also have occurred without intervening surgery). In fact, the small group differences in the amplitude of the late positivity were no longer apparent when different ERPs were compared (rare complex tone-frequent tone, Figure 5).

Finally, late positive ERP amplitude did not correlate with the extent of brain damage. Postoperative ERP amplitudes elicited by the rare complex tone (measured at $\mathrm{Cz}$ over the 200-350 ms latency range) were $8.9 \mu \mathrm{V}, 8.0 \mu \mathrm{V}, 9.5 \mu \mathrm{V},-1.3$ $\mu \mathrm{V},{ }^{1}$ and $15.2 \mu \mathrm{V}$ for the 5 monkeys listed in order of

'P3-like ERPs were not elicited from Monkey M4 during this recording session, which took place $2 \mathrm{hr}$ after a $0.2-\mathrm{cc}$ im injection of ketamine chloride $(100 \mathrm{mg} / \mathrm{ml})$. The injection was required for this particularly large monkey (weight approximately $6.5 \mathrm{~kg}$ ) in order to transfer him safely to the primate chair. No behavioral effects of the drug were apparent when recordings were made. This monkey was also immobilized prior to three subsequent recording sessions with a 


\section{-......FREQUENT TONE \\ - RARE TONE \\ RARE COMPLEX TONE

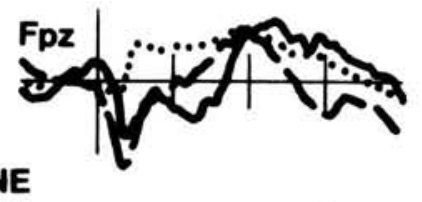

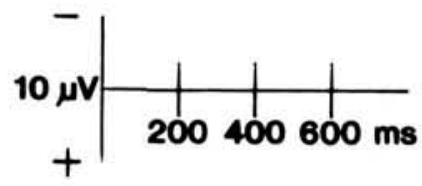
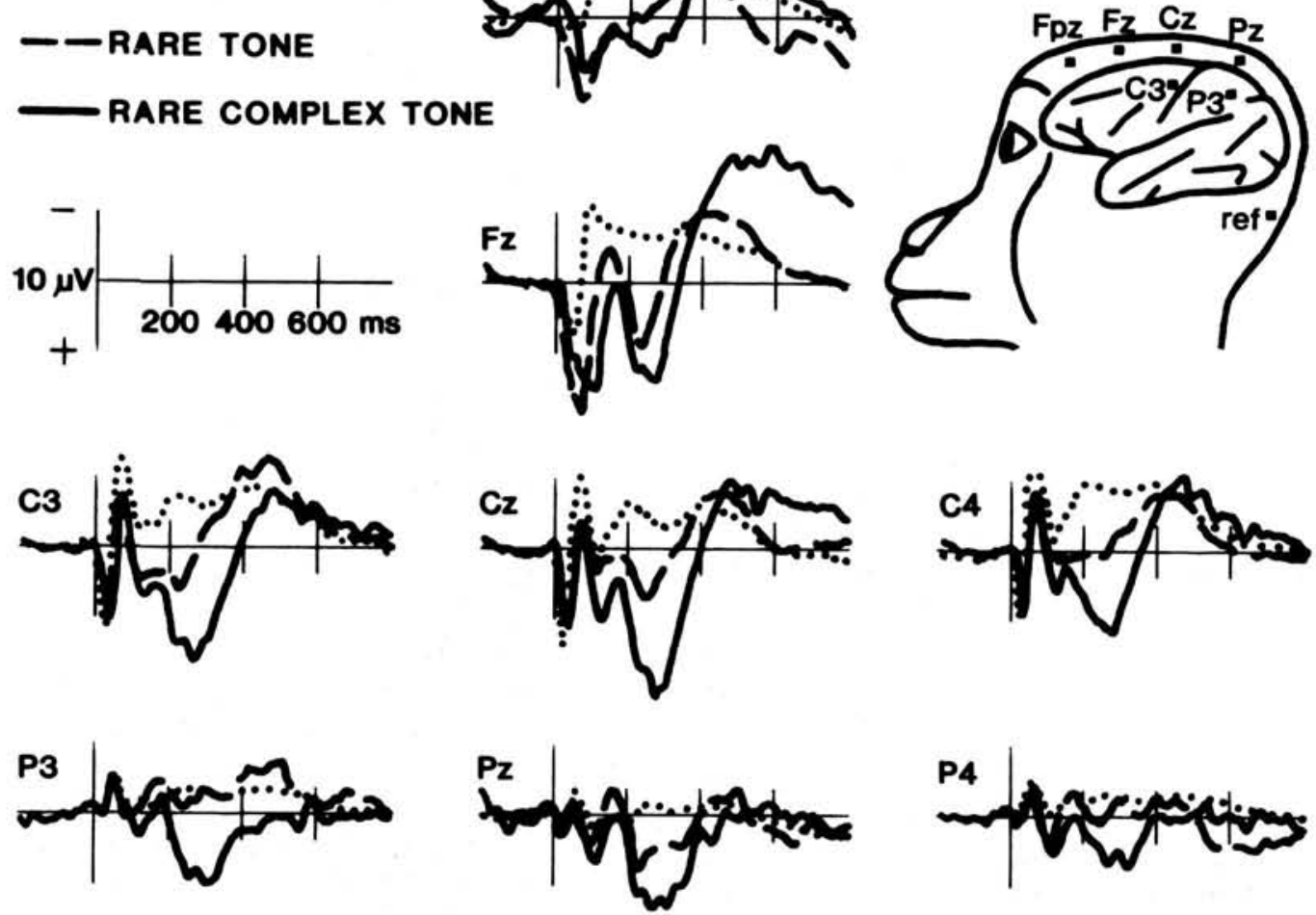

Figure 4. Event-related brain potentials elicited during the passive condition from a group of five monkeys with bilateral medial temporal lobectomies. $($ Ref $=$ reference electrode).

decreasing lesion size (Figure 2B). Despite the hypothesized role for the medial temporal lobe in generating P3, the integrity of hippocampus, amygdala, and adjacent cortex was not essential for the elicitation of late positive waves in the passive condition.

\section{Experiment 2: Active Condition}

P3 waves in humans are strongly influenced by the degree of attention paid to the stimuli; P3 amplitude is generally increased when stimuli have explicit relevance to an assigned task (see below). In the passive condition of Experiment 1, however, attention was not controlled. Accordingly, ERPs were also recorded in an active condition, in which a pitchdiscrimination task required manual responses to infrequent target tones interspersed in a sequence of nontarget tones.

\section{Method}

Animals. Two intact monkeys (one from Experiment 1) and two of the monkeys with medial temporal lesions (M2 and M5) were

stimulus sequence of frequent pure tones (90\%) and rare pure tones $(10 \%)$. In all instances, late positive ERPs were elicited by the rare pure tone, as was also the case. for the other members of the operated group. In Monkey M4, these waves occurred in the 100-250 ms latency range with a mean peak amplitude of $15.5 \mu \mathrm{V}$ at $\mathrm{Cz}$. See Paller (1986) for other results obtained using variations on the passive condition. studied. Water intake was restricted for at least one day before each training and recording session. Monkeys often received their entire liquid ration through task performance, but unlimited water was made available at least once a week.

Procedure. Monkeys were trained by operant techniques to pull a lever to initiate a sequence of identical nontarget tones. After a pseudorandom number of nontarget tones $(4,5,6,7$, or 8$)$, the target tone occurred. The target frequency was $300 \mathrm{~Hz}$, and the nontarget frequency was $1450 \mathrm{~Hz}$. All tones were $400 \mathrm{~ms}$ in duration. Releasing the lever in the interval 400-1,000 ms following target onset resulted in positive reinforcement (a 900 -ms noise burst followed by the delivery of a small amount of apple juice). Releasing the lever at any

Table 1

Measurements of Potentials Elicited in the Passive Condition in Intact and Lobectomy Groups

\begin{tabular}{lccr}
\hline & \multicolumn{3}{c}{ Electrode $^{\mathrm{A}}$} \\
\cline { 2 - 4 } Stimulus/Group & $\mathrm{Fz}$ & $\mathrm{Cz}$ & $\mathrm{Pz}$ \\
\hline Rare complex tone & & & \\
$\quad$ Intact & $7.1(2.5)$ & $11.2(2.3)$ & $6.9(2.3)$ \\
$\quad$ Lobectomy & $3.5(1.1)$ & $8.1(2.7)$ & $5.7(2.0)$ \\
Rare pure tone & & & \\
$\quad$ Intact & $2.4(2.7)$ & $4.9(2.4)$ & $3.5(0.9)$ \\
$\quad$ Lobectomy & $0.4(1.9)$ & $1.7(2.3)$ & $2.7(2.3)$ \\
Frequent pure tone & & & \\
$\quad$ Intact & $-0.1(0.6)$ & $0.7(0.6)$ & $2.0(0.6)$ \\
$\quad$ Lobectomy & $-3.4(0.8)$ & $-2.3(1.1)$ & $-0.6(0.8)$ \\
\hline
\end{tabular}

${ }^{a}$ Mean amplitude measurements (in $\mu \mathrm{V}$ ) over the 200-350 ms latency range (with standard errors); $N=5$ for both groups. 


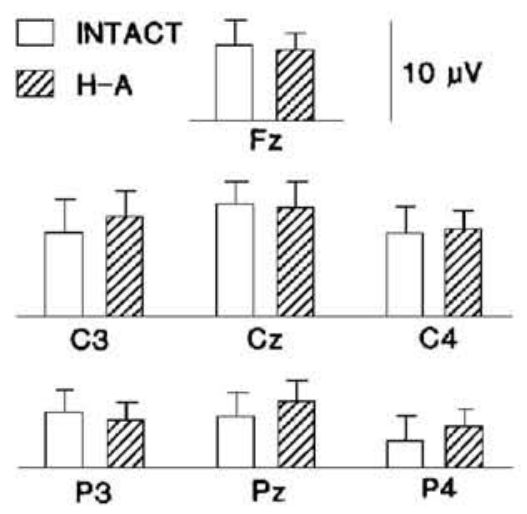

Figure 5. The topography of the difference in the $200-350 \mathrm{~ms}$ latency range between the event-related brain potential (ERP) to the rare complex tone and the ERP to the frequent tone (with standard errors) for the intact group and the group with bilateral medial temporal lobectomies $(\mathrm{H}-\mathrm{A})$, in the passive conditions.

other time resulted in negative reinforcement (a 3-s delay before the tone sequence could be initiated again). Responses made before tone offset were not rewarded in order to delay response artifacts.

ERPs obtained in the task condition were compared with ERPs elicited by the same stimuli during a no-task condition, in which task performance was not possible because the lever had been removed. Recordings were made in both conditions during each of four consecutive sessions. The order of the conditions was counterbalanced across sessions. For human subjects, recordings were made during one 20 -min session, in which the task condition was followed by the no-task condition.

\section{Results and Discussion}

Behavioral performance in the task condition showed that monkeys processed the stimuli at least to the extent necessary
Table 2

Measurements of Potentials Elicited in the Passive Condition Before and After Medial Temporal Lobectomy in Two Monkeys (M2 and M5)

\begin{tabular}{lrrr}
\hline & \multicolumn{3}{c}{ Electrode $^{\mathrm{a}}$} \\
\cline { 2 - 4 } Stimulus/Monkey & \multicolumn{1}{c}{$\mathrm{Fz}$} & $\mathrm{Cz}$ & $\mathrm{Pz}$ \\
\hline Rare complex tone & & & \\
M2: Intact & 11.1 & 16.8 & 10.6 \\
M2: Lobectomy & 5.2 & 8.0 & 6.9 \\
M5: Intact & -0.9 & 14.4 & 3.6 \\
M5: Lobectomy & 6.3 & 15.2 & 4.2 \\
\hline Rare pure tone & & & \\
M2: Intact & 4.8 & 4.8 & 5.7 \\
M2: Lobectomy & -4.4 & -2.0 & 0.0 \\
M5: Intact & 6.3 & 13.7 & 3.8 \\
M5: Lobectomy & 6.9 & 10.6 & 11.7 \\
\hline Frequent pure tone & \multicolumn{3}{c}{} \\
M2: Intact & 1.8 & 1.5 & 2.8 \\
M2: Lobectomy & -6.6 & -5.1 & -2.3 \\
M5: Intact & -0.3 & 2.3 & 3.0 \\
M5: Lobectomy & -2.8 & 0.1 & 1.7 \\
\hline Mean amplitude measurements (in $\mu \mathrm{V})$ over the $200-350 \mathrm{~ms}$ latency \\
range.
\end{tabular}

to make the target/nontarget discrimination. The 2 intact monkeys responded to $82 \%$ of the targets within $1 \mathrm{~s}$ (with a sensitivity index of $d^{\prime}=1.91$ ). The mean reaction time was $566 \mathrm{~ms}$. Because premature responses caused the tone sequence to be discontinued, the ratio of targets to nontargets decreased with the number of premature responses. Thus $12 \%$ of the total number of tones in the task condition were targets, whereas $17 \%$ of the total number of tones in the no-task condition were targets.

ERPs from the intact monkeys are shown in Figure 7 for both conditions. Large late positive ERPs were elicited only

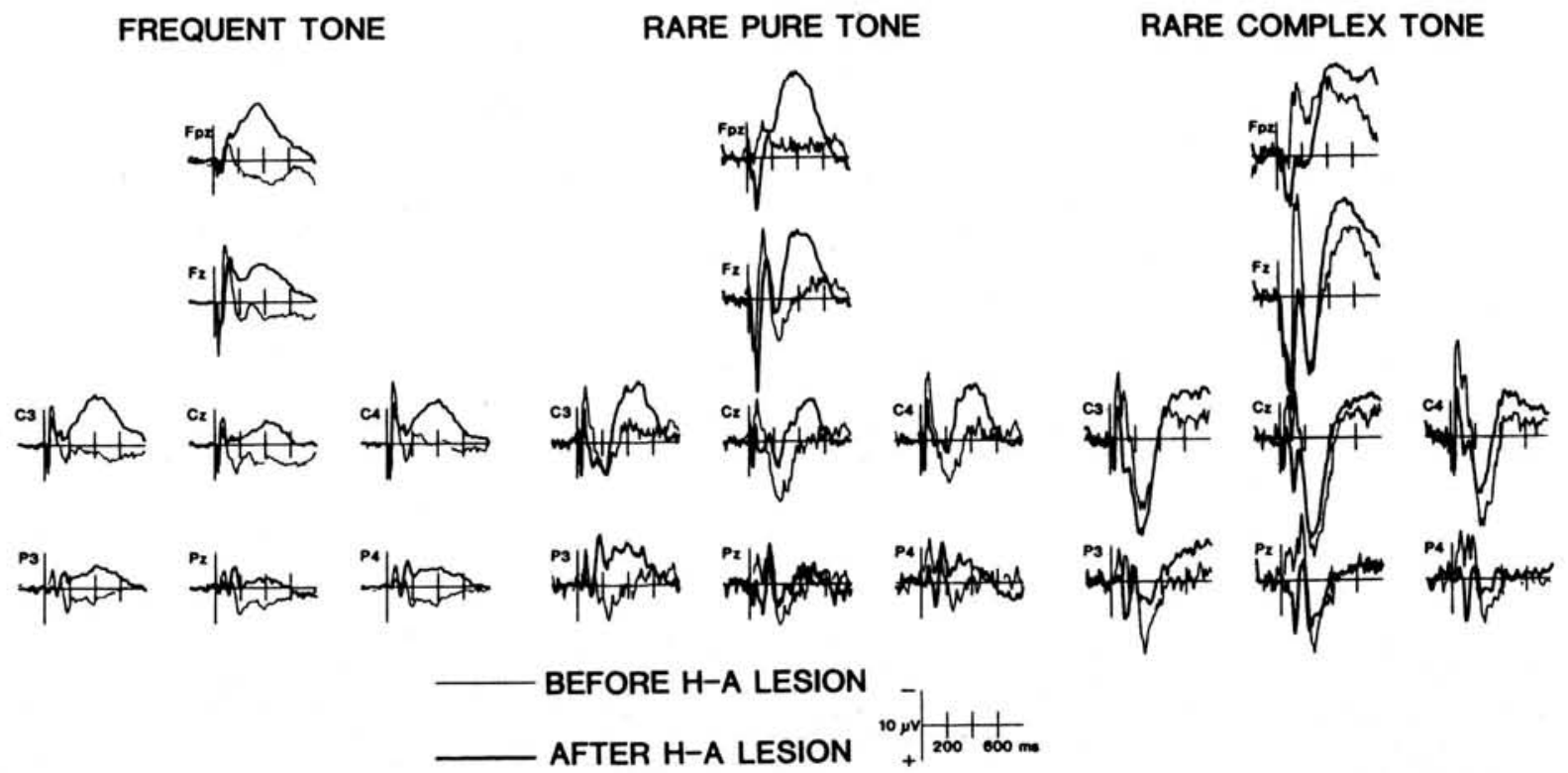

Figure 6. Event-related brain potentials elicited during the passive condition from a group of two monkeys, before and after medial temporal lobectomy $(\mathrm{H}-\mathrm{A})$ lesions. 

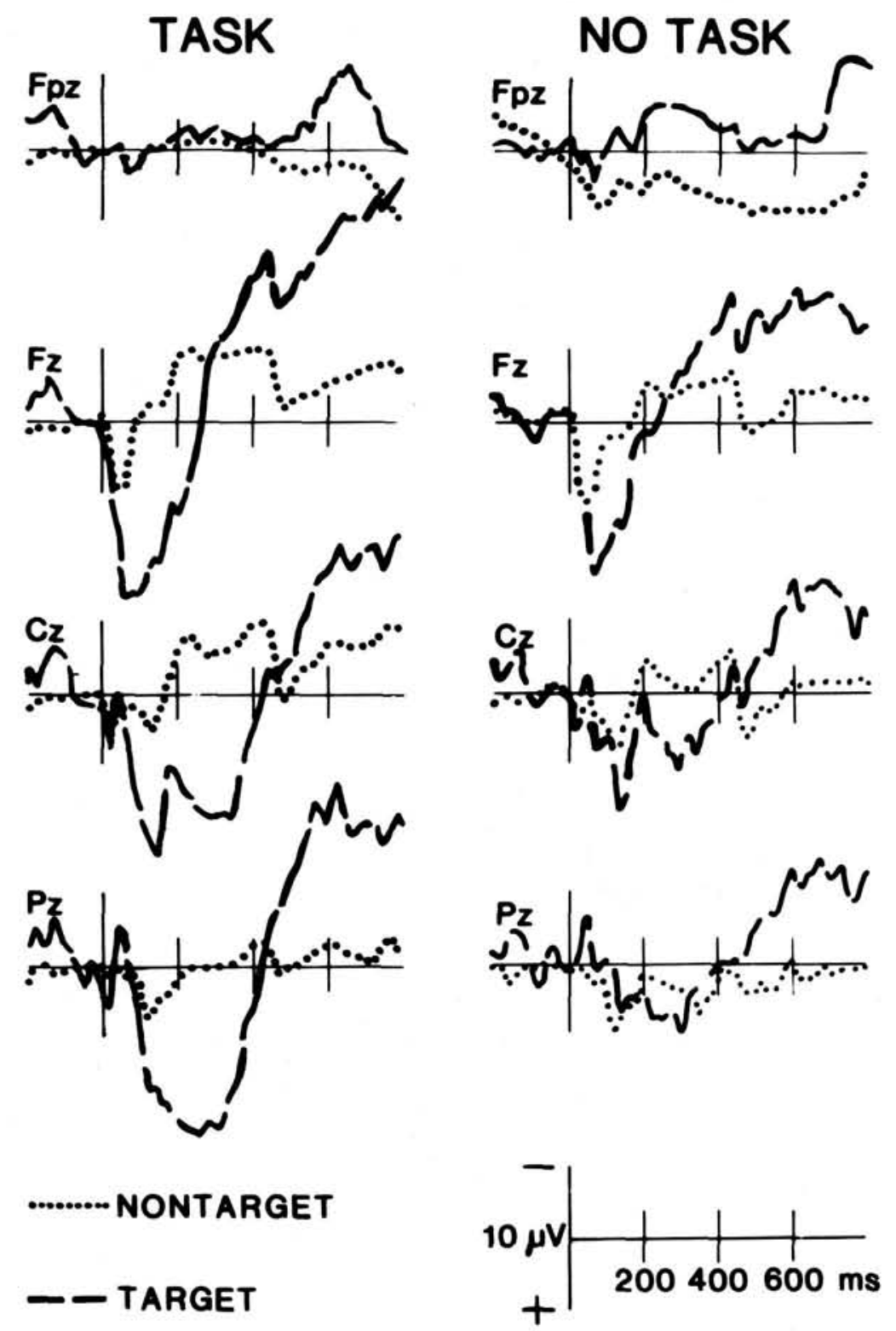

Figure 7. Event-related brain potentials elicited during the active condition from a group of two intact monkeys. (For one monkey, the channel labeled Fpz was recorded with subdermal electrodes above and below the right eye.)

by the target. Furthermore, this positive activity was greater during performance of the task than in the no-task condition. ${ }^{2}$ This enhanced positivity in the task condition was observed in intact monkeys, as well as in $\mathbf{2}$ monkeys with medial temporal lobectomies and in a group of human subjects (see Table 3). Although the amplitude and the peak latency of P3like ERPs in the task condition were greater in monkeys with medial temporal lesions than in intact monkeys, the reliability of these differences is questionable owing to the small number of subjects. Notwithstanding these differences, P3-like ERPs in the 2 intact and 2 operated monkeys were clearly enhanced during task performance, $F(1,3)=28.4, p<.013$, based on measurements of target minus nontarget difference ERPs in the 200-350 ms latency range at midline electrodes.
Further comment is in order concerning the influence of task requirements on P3. P3 waves with a parietal amplitude maximum are typically elicited in humans who are required to detect, count, or respond overtly to infrequent events. Experiments without explicit task requirements have yielded variable results. Stimuli irrelevant to a behavioral task have elicited either no late positivity (Desmedt \& Debecker, 1979; Donchin \& Cohen, 1967; Duncan-Johnson \& Donchin, 1977; Hansen \& Hillyard, 1984), positivity with a shorter latency and a more frontal topography, sometimes designated P3a

\footnotetext{
${ }^{2}$ Results from a tone-frequency manipulation in one monkey showed that P3-like ERPs were associated with a tone's role as target rather than with its particular frequency (Paller, 1986).
} 
Table 3

Measurements of Potentials Elicited in the Active Condition

\begin{tabular}{ccrr}
\hline & \multicolumn{3}{c}{ Electrode $^{\mathrm{a}}$} \\
\cline { 2 - 4 } Group/Condition & $\mathrm{Fz}$ & $\mathrm{Cz}$ & $\mathrm{Pz}$ \\
\hline Intact & & & \\
Task & 5.3 & 13.3 & 11.1 \\
No Task & 0.3 & 5.2 & 2.8 \\
Lobectomy & & & \\
Task & 9.7 & 23.2 & 12.4 \\
No Task & 0.1 & 14.0 & 7.4 \\
Human & & & \\
Task & 6.5 & 13.9 & 14.0 \\
No Task & 6.3 & 10.5 & 8.0
\end{tabular}

a Mean amplitude measurements (in $\mu \mathrm{V}$ ) over the 200-350 ms latency range for the target minus nontarget difference; $N=2$ for the two monkey groups, and $N=8$ for the human group.

(Knight, 1984; Snyder \& Hillyard, 1976; Squires et al., 1975), or a long-latency, parietal-dominant P3, also known as P3b (Ford, Roth, \& Kopell, 1976; Ritter, Vaughan, \& Costa, 1968; Roth, Ford, Lewis, \& Kopell, 1976; Smith, Donchin, Cohen, \& Starr, 1970; Squires, Donchin, Squires, \& Grossberg, 1977). One factor likely to account for some of the differences among these studies is the nature of the distraction tasks and/or instructions given to the subject. That is, instructions to ignore stimuli may disrupt the information processing necessary for P3b, but only if enough attentional resources have been diverted to other processing activities and are not available to process the infrequent events. Evidence from an experiment with two concurrent tasks (Wickens et al., 1983) is consistent with this idea, in that P3 amplitude to stimuli in the primary task decreased as the processing demands of the secondary task increased.

The finding that the amplitude of P3-like ERPs in monkeys and in humans was smaller in the no-task condition than in the task condition is consistent with the literature on P3 and provides further support for the cross-species parallel. Likewise, the finding of large, P3-like ERPs in the passive condition of Experiment 1 is also consistent with many previous reports. Although human and monkey subjects were not required to pay attention in the passive condition, it is reasonable to presume that subjects were attending to the stimuli at least part of the time. In both experimental conditions, the P3-like responses may have included components homologous to $\mathrm{P} 3 \mathrm{a}$ and $\mathrm{P} 3 \mathrm{~b}$, but a rigorous separation of these components is not possible here.

\section{General Discussion}

\section{An Animal Model of $P 3$}

Late positive ERPs were elicited by rare tones in all monkeys studied, whether in the passive condition or in the active condition. These ERPs were similar to P3 waves in humans in latency, polarity, topography, and general waveshape. In addition to these waveform characteristics, a correspondence was also demonstrated for functional characteristics (i.e., relations to stimulus and task variables and, inferentially, to cognitive functions). P3-like ERPs were elicited by two types of infrequent tones and were largest to complex tones. Furthermore, P3-like ERPs elicited by targets in a discrimination task were enhanced relative to ERPs elicited by the same stimuli when the task was not being performed.

These results are in accordance with similar findings in other monkey species. In the squirrel monkey (Saimiri sciureus), P3-like ERPs were elicited by infrequent auditory stimuli in a condition analogous to the passive condition described above (Neville \& Foote, 1984; Pineda et al., 1987). In Macaca nemestrina (a species closely related to Macaca fascicularis), P3-like ERPs were elicited by rare target tones in a pitch-discrimination task similar to the one used in the present study (Arthur \& Starr, 1984).

A number of other studies of possible animal homologs of P3 waves have utilized classical conditioning paradigms. ${ }^{3}$ Such studies have been carried out in monkeys (Glover, Onofrj, Ghilardi, \& Bodis-Wollner, 1986), paralyzed cats (O'Conner \& Starr, 1985; Wilder, Farley, \& Starr, 1981), awake cats (Buchwald \& Squires, 1981), rabbits (Gabriel, Sparenborg, \& Donchin, 1983; Weisz, McCarthy, Wood, \& Thompson, 1983), and a bottlenose dolphin (Woods, Ridgway, Carter, \& Bullock, 1985). Interpretation of these results is problematic, however, because task requirements and behavioral measures were quite different from those studied in conventional P3 paradigms in humans. For example, although the pupillary or blink responses elicited in cats do reflect conditioned associations, they do not necessarily entail the same processing that is required for the discriminative responses generally elicited in humans. Whereas functional characteristics are crucial for defining P3 waves, ultimately these characteristics must be mapped onto physiological processes as the neural circuitry underlying ERPs is identified.

In sum, ERPs recorded from monkeys have revealed stronger similarities to $\mathrm{P} 3$ waves in humans than have been demonstrated in other nonhuman species. The cross-species parallels demonstrated in Experiments 1 and 2 suggest that the late positive waves may reflect common (or homologous) neurophysiological processes in monkeys and humans.

\section{Effects of Medial Temporal Lesions on P3-like ERPS}

The elicitation of P3-like ERPs in monkeys did not require the integrity of the hippocampus, amygdala, or adjacent cortical areas. ERPs elicited from monkeys with bilateral lesions of the medial temporal lobe retained the basic similarities to human $\mathbf{P} 3$ waves that were demonstrated in intact monkeys. These ERPs were elicited from operated monkeys both in passive and active conditions. Although there was no reliable

\footnotetext{
${ }^{3}$ A study reported by Aleksandrov and Maksimova (1985) is also notable, in that P3-like ERPs were obtained from rabbits trained in a signal-detection task. Although most studies of P3-like ERPs in animals have not focussed on their neural sources, in two recent reports researchers have described intriguing results following lesions: In cats, the acetylcholine system of the medial septal area has been implicated (Harrison, Buchwald, Kaga, Woolf, \& Butcher, 1988); and in squirrel monkeys, the norepinephrine system of the locus coeruleus has been implicated (Pineda, Foote, \& Neville, in press).
} 
evidence for an effect of the medial temporal lobectomy on the surface-recorded P3-like ERPs, the present results cannot rule out a small contribution from these brain areas.

This finding may seem surprising in view of reports that electrical activity is generated within medial temporal lobe structures coincident with scalp-recorded $\mathrm{P} 3$ waves in humans (Halgren et al., 1980; Okada et al., 1983; Wood et al., 1984). The present results suggest that this intracranial activity may not make a major contribution to the generation of the P3like ERPs recorded at the scalp. Thus, given that the late positive ERP in monkeys constitutes a valid animal model of P3 in humans, the present results imply that much of the neural activity that gives rise to the scalp-recorded P3 is localized in brain areas other than the medial temporal lobe. Recent results obtained from human epileptic patients are also consistent with this conclusion; patients with unilateral surgical lesions of the temporal lobe exhibited P3 waves that did not show the prominent field asymmetries that would be expected if $\mathbf{P} 3$ were generated solely in the medial temporal lobe (Johnson \& Fedio, 1984; Stapleton, Halgren, \& Moreno, 1987; Wood et al., 1982). Further studies of such patients have suggested that $P 3$ waves may be altered at extreme lateral scalp locations on the side of focal temporal lobe pathology (McCarthy, Darcey, Wood, Williamson, \& Spencer, 1987). In the present study, electrodes were not placed at extreme lateral locations because those parts of the skull were removed in performing the lobectomy. Nevertheless, in epileptic patients with unilateral lesions and in monkeys with bilateral lesions, P3-like activity was essentially unchanged in midline surface recordings, where its amplitude is largest. Such a convergence between results from studies in humans and in monkeys enhances the validity of the animal model and holds promise for further improvements in our understanding of the neural bases of $\mathrm{P} 3$ waves and the associated cognitive processes.

\section{References}

Aleksandrov, I. O., \& Maksimova, N. E. (1985). P300 and the psychophysiological analysis of the structure of behavior. Electroencephalography and Clinical Neurophysiology, 61, 548-558.

Arthur, D. L., \& Starr, A. (1984). Task-relevant late positive component of the auditory event-related potential in monkeys resembles P300 in humans. Science, 223, 186-188.

Begleiter, H., \& Porjesz, B. (1986). The P300 component of the eventrelated brain potential in psychiatric patients. In R. Q. Cracco \& I. Bodis-Wollner (Eds.), Evoked potentials: Frontiers of clinical neuroscience (Vol. 3, pp. 529-535). New York: Liss.

Bonin, G. V., \& Bailey, P. (1947). The neocortex of Macaca mulatta. Urbana, IL: University of Illinois Press.

Buchwald, J. S., \& Squires, N. S. (1981). Endogenous auditory potentials in the cat: A P300 model. In C. D. Woody (Ed.), Conditioning: Representation of the involved neural function (pp. 503-515). New York: Plenum.

Desmedt, J. E. (1981). Scalp-recorded cerebral event-related potentials in man as point of entry into the analysis of cognitive processing. In F. O. Schmitt, F. G. Worden, G. Adelman, \& S. D. Dennis (Eds.), The organization of the cerebral cortex (pp. 441-473). Cambridge, MA: MIT.

Desmedt, J. E., \& Debecker, J. (1979). Waveform and neural mechanisms of the decision P350 elicited without prestimulus CNV or readiness potential in random sequences of near-threshold auditory clicks and finger stimuli. Electroencephalography and Clinical Neurophysiology, 47, 648-670.

Donchin, E. (1981). Surprise! ... surprise? Psychophysiology, 18, 493-513.

Donchin, E. (Ed.). (1984). Cognitive psychophysiology: Event-related potentials and the study of cognition. Hillsdale, NJ: Erlbaum.

Donchin, E., \& Cohen, L. (1967). Averaged evoked potentials and intramodality selective attention. Electroencephalography and Clinical Neurophysiology, 22, 537-546.

Douglas, R. J. (1967). The hippocampus and behavior. Psychological Bulletin, 67, 416-442.

Duncan-Johnson, C. C., \& Donchin, E. (1977). On quantifying surprise: The variation of event-related potentials with subjective probability. Psychophysiology, 14, 456-467.

Fabiani, M., Gratton, G., Karis, D., \& Donchin, E. (1987). The definition, identification, and reliability of measurement of the P300 component of the event-related brain potential. In P. K. Ackles, J. R. Jennings, \& M. G. H. Coles (Eds.), Advances in psychophysiology (Vol. 2, pp. 1-78). Greenwich, CT: JAI Press.

Fabiani, M., Karis, D., \& Donchin, E. (1986). P300 and recall in an incidental memory paradigm. Psychophysiology, 23, 298-308.

Ford, J. M., Roth, W. T., \& Kopell, B. S. (1976). Auditory evoked potentials to unpredictable shifts in pitch. Psychophysiology, 13, 32-39.

Gabriel, M., Sparenborg, S. P., Donchin, E. (1983). Macropotentials recorded from the cingulate cortex and anterior thalamus in rabbits during the "oddball" paradigm used to elicit P300 in humans. Society for Neuroscience Abstracts, 9, 1200.

Gaillard, A. W. K., \& Ritter, W. (Eds.). (1983). Tutorials in eventrelated potential research: Endogenous components. Amsterdam: North-Holland.

Galambos, R., \& Hillyard, S. A. (1981). Electrophysiological approaches to human cognitive processing. Neurosciences Research Program Bulletin, 20, 141-265.

Glover, A. A., Onofrj, M. C., Ghilardi, M. F., \& Bodis-Wollner, I. (1986). P300-like potentials in the normal monkey using classical conditioning and an auditory "oddball" paradigm. Electroencephalography and Clinical Neurophysiology, 65, 231-235.

Halgren, E., Squires, N. K., Wilson, C. L., Rohrbaugh, J. W., Babb, T. L., \& Crandall, P. H. (1980). Endogenous potentials generated in the human hippocampal formation and amygdala by infrequent events. Science, 210, 803-805.

Halgren, E., Wilson, C. L., Squires, N. K., Engel, J., Jr., Walter, R. D., \& Crandal, P. H. (1983). Dynamics of the human hippocampal contribution to memory. In W. Seifert (Ed.), Neurobiology of the hippocampus (pp. 529-572). London: Academic Press.

Hansen, J. C., \& Hillyard, S. A. (1984). Effects of stimulation rate and attribute cueing on event-related potentials during selective auditory attention. Psychophysiology, 21, 394-405.

Harrison, J. B., Buchwald, J. S., Kaga, K., Woolf, N. J., \& Butcher, L. L. (1988). Cat "P300" disappears after septal lesions Electroencephalography and Clinical Neurophysiology, 69, 55-64.

Hillyard, S. A., \& Kutas, M. (1983). Electrophysiology of cognitive processing. Annual Review of Psychology, 34, 33-61.

Hillyard, S. A., Squires, K. C., Bauer, J. W., \& Lindsay, P. H. (1971). Evoked potential correlates of auditory signal detection. Science, $172,1357-1360$.

Jasper, H. H. (1958). Report to the committee on methods of clinical examination in electroencephalography. Appendix: The ten-twenty system of the International Federation. Electroencephalography and Clinical Neurophysiology, 10, 371-375.

Johnson, R., Jr., \& Fedio, P. (1984). ERP and P300 activity in patients following unilateral temporal lobectomy. Society for Neuroscience Abstracts, 10,847.

Karis, D., Fabiani, M., \& Donchin, E. (1984). "P300" and memory: 
Individual differences in the von Restorff effect. Cognitive Psychology, 16, 177-216.

Karrer, R., Cohen, J., \& Tueting, P. (Eds.). (1984). Brain and information: Event-related potentials. New York: The New York Academy of Sciences.

Knight, R. T. (1984). Decreased responses to novel stimuli after prefrontal lesions in man. Electroencephalography and Clinical Neurophysiology, 59, 9-20.

Kutas, M., \& Hillyard, S. A. (1985). Event-related potentials and psychopathology. In J. O. Cavenar, Jr. (Ed.), Psychiatry, Vol. 3 (pp. 1-17). Philadelphia: Lippincott/Harper \& Row.

Kutas, M., McCarthy, G., \& Donchin, E. (1977). Augmenting mental chronometry: The $\mathrm{P} 300$ as a measure of stimulus evaluation time. Science, 197, 792-795.

McCarthy, G., Darcey, T. M., Wood, C. C., Williamson, P. D., \& Spencer, D. D. (1987). Asymmetries in scalp and intracranial endogenous ERPs in patients with complex partial epilepsy. In $\mathbf{J}$. Engel, Jr. et al. (Eds.), Fundamental mechanisms of human brain function (pp. 51-59). New York: Raven.

McCarthy, G., \& Donchin, E. (1981). A metric for thought: A comparison of $\mathrm{P} 300$ latency and reaction time. Science, 211, 7780.

Meissner, W. W. (1966). Hippocampal functions in learning. Journal of Psychiatric Research. 4, 235-304.

Michalewski, H. J., Rosenberg, C., \& Starr, A. (1986). Event-related potentials in dementia. In R. Q. Cracco \& I. Bodis-Wollner (Eds.), Evoked potentials: Frontiers of clinical neuroscience, Vol. 3 (pp. 521-528). New York: Liss.

Mishkin, M. (1978). Memory in monkeys severely impaired by combined but not separate removal of amygdala and hippocampus. Naiure, 273, 297-298.

Neville, H. J., \& Foote, S. L. (1984). Auditory event-related potentials in the squirrel monkey: Parallels to human late wave responses. Brain Research, 298, 107-116.

Neville, H. J., Kutas, M., Chesney, G., \& Schmidt, A. L. (1986). Event-related brain potentials during initial encoding and recognition memory of congruous and incongruous words. Memory and Language, 25, 75-92.

O'Conner, T., \& Starr, A. (1985). Intracranial potentials correlated with an event-related potential, P300, in the cat. Brain Research, $339,27-38$.

Okada, Y. C., Kaufman, L., \& Williamson, S. J. (1983). The hippocampal formation as a source of the slow endogenous potentials. Electroencephalography and Clinical Neurophysiology, 55. 417426.

O'Keefe, J., \& Nadel, L. (1978). The hippocampus as a cognitive map. Oxford: Clarendon Press.

Paller, K. A. (1986). Effects of medial temporal lobectomy in monkeys on brain potentials related to memory (Doctoral dissertation, University of California, San Diego, 1986). Dissertation Abstracts International, 47, 4428B.

Paller, K. A., Kutas, M., \& Mayes, A. (1987). Neural correlates of encoding in an incidental learning paradigm. Electroencephalography and Clinical Neurophysiology, 67, 360-371.

Paller, K. A., Zola-Morgan, S., Squire, L. R., \& Hillyard, S. A. (1982). Late positive event-related potentials in cynomolgus monkeys ( $\mathrm{Ma}$ caca fascicularis). Society for Neuroscience Abstracts, 8, 975.

Paller, K. A., Zola-Morgan, S., Squire, L. R., \& Hillyard, S. A. (1984). Monkeys with lesions of hippocampus and amygdala exhibit eventrelated brain potentials that resemble the human P300 wave. Society for Neuroscience Abstracts, 10, 849.

Pineda, J. A., Foote, S. L., \& Neville, H. J. (1987). Long-latency event-related potentials in squirrel monkeys: Further characterization of wave form morphology, topography, and functional properties. Electroencephalography and Clinical Neurophysiology, 67. 77-90.
Pineda, J. A., Foote, S. L., \& Neville, H. J. (in press). Effect of locus coeruleus lesions in auditory, long-latency, event-related potentials in monkey. Journal of Neuroscience.

Pritchard, W. S. (1981). Psychophysiology of P300: A review. Psychological Bulletin, 89, 506-540.

Ritter, W., Vaughan, H. G., Jr., \& Costa, L. D. (1968). Orienting and habituation to auditory stimuli: A study of short term changes in average evoked responses. Electroencephalography and Clinical Neurophysiology, 25, 550-556.

Rohrbaugh, J. W., \& Gaillard, A. W. K. (1983). Sensory and motor aspects of the contingent negative variation. In A. W. K. Gaillard \& W. Ritter (Eds.), Tutorials in ERP research: Endogenous components (pp. 269-310). Amsterdam: North-Holland.

Roth, W. T., Ford, J. M., Lewis, S. J., \& Kopell, B. S. (1976). Effects of stimulus probability and task-relevance on event-related potentials. Psychophysiology, 13, 311-317.

Ruchkin, D. E., \& Sutton, S. (1978). Emitted P300 potentials and temporal uncertainty. Electroencephalography and Clinical Neurophysiology, 45, 268-277.

Sanquist, T. F., Rohrbaugh, J. W., Syndulko, K., \& Lindsley, D. B. (1980). Electrocortical signs of levels of processing: Perceptual analysis and recognition memory. Psychophysiology, 17, 568-576.

Scoville, W. B., \& Milner, B. (1957). Loss of recent memory after bilateral hippocampal lesions. Journal of Neurology and Psychiatry, 20, 11-21.

Smith, D. B. D., Donchin, E., Cohen, L., \& Starr, A. (1970). Auditory averaged evoked potentials in man during selective binaural listening. Electroencephalography and Clinical Neurophysiology, 28, 146-152.

Snyder, E., \& Hillyard, S. A. (1976). Long-latency evoked potentials to irrelevant deviant stimuli. Behavioral Biology, 16, 319-331.

Snyder, E., Hillyard, S. A., \& Galambos, R. (1980). Similarities and differences among the $P 3$ waves to detected signals in three modal. ities. Psychophysiology, 17, 112-122.

Squires, N. K., Donchin, E., Squires, K. C., \& Grossberg, S. (1977). Bisensory stimulation: Inferring decision-related processes from the P300 component. Journal of Experimental Psychology: Human Perception and Performance, 3, 299-315.

Squires, N. K., Squires, K. C., \& Hillyard, S. A. (1975). Two varieties of long-latency positive waves evoked by unpredictable auditory stimuli in man. Electroencephalography and Clinical Neurophysiology, 38, 387-401.

Stapleton, J. M., Halgren, E., \& Moreno, K. A. (1987). Endogenous potentials after anterior temporal lobectomy. Neuropsychologia, $25,549-557$.

Sutton, S., \& Ruchkin, D. S. (1984). The late positive complex: Advances and new problems. In R. Karrer, J. Cohen, \& P. Tueting (Eds.), Brain and information: Event-related potentials (pp. 1-23). New York: The New York Academy of Sciences.

Sutton, S., Tueting, P., Zubin, J., \& John, E. R. (1967). Information delivery and the sensory evoked potential. Science, 155, 14361439.

Vaughan, H. G., \& Arezzo, J. C. (1988). The neural basis of eventrelated potentials. In T. W. Picton (Ed.), Handbook of electroencephalogy and clinical neurophysiology: Human event-related potentials (Vol. 3, pp. 45-96). Amsterdam: Elsevier.

Vaughan, H. G., \& Ritter, W. (1970). The sources of auditory evoked responses recorded from the human head. Electroencephalography and Clinical Neurophysiology, 28, 360-367.

Vinogradova, O. S. (1970). The hippocampus and the orienting reflex. In E. N. Sokolov \& O. S. Vinogradova (Eds.), Neuronal mechanisms of the orienting reflex (pp. 128-154). Hillsdale, NJ: Erlbaum.

Weisz, D. J., McCarthy, G., Wood, C. C., \& Thompson, D. T. (1983). Event-related potentials reflect stimulus significance during discriminative NM conditioning in the rabbit. Society for Neuroscience Abstracts, 9, 642 . 
Wickens, C., Kramer, A., Vanasse, L., \& Donchin, E. (1983). Performance of concurrent tasks: A psychological analysis of the reciprocity of information-processing resources. Science, 221, 1080-1082.

Wilder, M. B., Farley, G. R., \& Starr, A. (1981). Endogenous late positive component of the evoked potential in cats corresponding to P300 in humans. Science, 211, 605-607.

Wood, C. C., McCarthy, G., Allison, T., Goff, W. R., Williamson, P. D., \& Spencer, D. D. (1982). Endogenous event-related potentials following temporal lobe excisions in humans. Society for Neuroscience Abstracts, 8, 976.

Wood, C. C., McCarthy, G., Squires, N. K., Vaughan, H. G., Woods, D. L., \& McCallum, W. C. (1984). Anatomical and physiological substrates of event-related potentials: Two case studies. In $\mathbf{R}$. Karrer, J, Cohen, \& P. Tueting (Eds.), Brain and information: Event-related potentials (pp. 681-721). New York: The New York Academy of Sciences.

Woods, D. L., Ridgway, S. H., Carter, D. G., \& Bullock, T. H. (1985).
Middle- and long-latency auditory event-related potentials in dolphins. In R. J. Schusterman, J. A. Thomas, \& F. G. Wood (Eds.), Dolphin cognition and behavior: A comparative approach (pp. 6178). Hillsdale, NJ: Erlbaum.

Zola-Morgan, S., \& Squire, L. R. (1985). Medial temporal lesions in monkeys impair memory on a variety of tasks sensitive to human amnesia. Behavioral Neuroscience, 99, 22-34.

Zola-Morgan, S., Squire, L. R., \& Amaral, D. G. (1986). Human amnesia and the medial temporal region: Enduring memory impairment following a bilateral lesion limited to field CAl of the hippocampus. Journal of Neuroscience, 6, 2950-2967.

Zola-Morgan, S., Squire, L. R., \& Mishkin, M. (1982). The neuroanatomy of amnesia: Amygdala-hippocampus versus temporal stem. Science, 218, 1337-1339.

Received September 11, 1986 Revision received August 4, 1987 Accepted August 5, 1987

\title{
Hunt Appointed Editor of JEP: General, 1990-1995
}

The Publications and Communications Board of the American Psychological Association announces the appointment of Earl B. Hunt, University of Washington, as editor of the Journal of Experimental Psychology: General for a 6-year term beginning in 1990. As of January 1, 1989, manuscripts should be directed to

\author{
Earl B. Hunt \\ Department of Psychology NI-25 \\ University of Washington \\ Seattle, Washington 98195
}

Manuscript submission patterns for JEP: General make the precise date of completion of the 1989 volume uncertain. The current editor, Sam Glucksberg, will receive and consider manuscripts until December 31, 1988. Should the 1989 volume be completed before that date, manuscripts will be redirected to Hunt for consideration in the 1990 volume. 